\title{
A ODIENTA DIREITA BRASILEIRA: ELEMENTOS PARA SUA COMPREENSÃO
}

Resenha de: GALLEGO, Esther S. (Org). O ódio como política: a reinvenção das direitas no Brasil. São Paulo: Boitempo, 2018. 118p.

\section{Vitor Hugo Rinaldini Guidotti ${ }^{1}$}

Recebido em: 30/08/2019

http://lattes.cnpq.br/3171646123025674

Aceito em: 25/11/2019

Nos últimos anos, especialmente após as jornadas de junho de 2013, a sociedade brasileira vivencia um fervoroso recrudescimento de vozes abertamente conservadoras, intolerantes e até mesmo antidemocráticas. Se o objetivo for garantir a dignidade da pessoa humana e combater seus aviltamentos, a afirmação que prossegue não pode estar mais correta: há uma necessidade compreensiva da conjuntura sociopolítica, cujo um dos escopos possíveis se refere ao ódio manifestado por uma significativa parcela de grupos que compõem o espectro político de direita no Brasil.

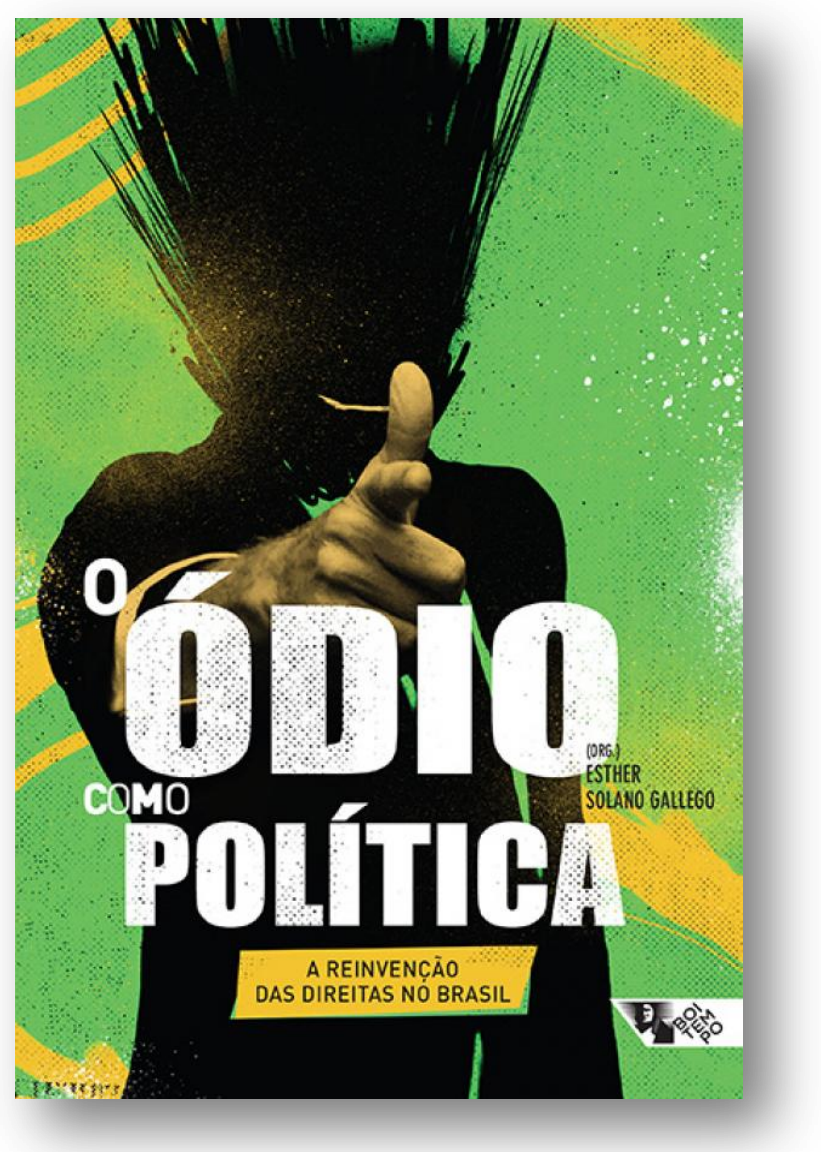

Felizmente, a obra organizada pela socióloga e professora da Universidade Federal de São Paulo (UNIFESP), Esther Solano Gallego, ao superar tanto anti-intelectualismo reacionário quanto o academicismo incompreensível fora dos muros das Universidades oferece um conjunto de reflexões que possibilita um vislumbre ao Brasil sombrio de hoje.

A obra compõe a coleção Tinta Vermelha da editora Boitempo, uma série de publicações que visa compreender acontecimentos contemporâneos, sejam nacionais ou internacionais. Além do prólogo provocativo escrito por Gregório Duvivier e a apresentação redigida pela organizadora, este sexto volume é composto por 15 textos e traz charges que retratam, denunciam e refletem a sociedade e a política brasileira atual, uma combinação de escritos e arte que consubstancia uma obra tão necessária. Deste modo, o objetivo desta resenha foi percorrer sinopticamente os textos dos/as

\footnotetext{
${ }^{1}$ Doutorando em Sociologia pela Universidade Federal de São Carlos. Mestre em Sociologia pela Universidade Federal da Grande Dourados (UFGD). Endereço eletrônico: vitor_guidotti@live.com.
} 
acadêmicos/as e progressistas que dão corpo ao livro.

Luis Felipe Miguel, pesquisador e professor da Universidade de Brasília (UnB), abre o conjunto de reflexões com o texto intitulado A reemergência da direita brasileira. Miguel traça uma perspectiva dos governos do Partido dos Trabalhadores (PT) e suas estratégias conciliatórias de governabilidade, estas que não surtiram os efeitos esperados pelo partido. Com o contínuo enfraquecimento do PT à frente do governo, Miguel aponta que grupos de direita perceberam a possibilidade de "radicalizar seu discurso" (p. 19). O pesquisador divide em três categorias mais extremadas que reemergem a direita brasileira, que são o libertarianismo, o fundamentalismo religioso e o antigo anticomunismo. Estes grupos, segundo o autor, não são estanques e tendem a reunir esforços no combate às perspectivas sociais progressistas e de esquerda. Toda essa conjuntura de avanço radical da direita política culminou no seu domínio do debate público, que procura contestar os avanços - tímidos - produzidos pelo PT no que diz respeito às políticas públicas criadas nos últimos anos de combate à desigualdade social e à discriminação face as diferenças, minando, assim, o projeto de um Brasil mais justo.

Em Neoconservadorismo e liberalismo, Silvio Luiz de Almeida, advogado e professor universitário, nos explica os conceitos de conservadorismo ${ }^{2}$ e de liberalismo, bem como a história da ascensão destas ideologias. Almeida busca a gênese teórica e os acontecimentos políticos para explicar as novas pautas de liberais e conservadores contemporâneos. Segundo o autor as transformações e a atualização que ocorrera com os conservadores e liberais são as táticas empregadas para manter a condição de produção e reprodução do capitalismo intacto, extirpando as ameaças que enfraquecem as formas sociais de sua manutenção. Concluí que a democracia não representa um valor universal, e mais contribui para reforçar "[...] a ideia de unidade e de coesão social" (p. 31) em um contexto de controle pelo modo de produção que o capitalismo impõe as sociedades de todo o globo. A superação do neoconservadorismo e do discurso neoliberal, segundo Almeida, não passa somente pela desqualificação de seus discursos frágeis, mas também pela "[...] transformação das condições socioeconômicas que lhe fornece a base material" (p. 27).

Em sequência o texto de Carapanã, um pseudônimo usado por um autor anônimo, cujo título é A nova direita e a normalização do nazismo e do fascismo, apresenta um panorama das direitas no mundo, suas estratégias de ação e os impactos perpetrados por estas frentes no debate público mundial. Interessante notar que a abordagem que Carapanã faz sobre a perspectiva de Estado e economia se assemelha ao raciocínio do texto anterior, de Silvio Luiz de Almeida, ao explicitar que a nova direita procura criticar o caráter redistributivo do Estado e "privatizá-lo" de acordo com os interesses do mercado, isto é, da classe dominante. Em outras palavras, "o Estado que deve ser atacado não é aquele das máquinas de guerra, da repressão policial ou do desrespeito aos cidadãos", mas sim aquele que "[...] concederia direitos demais - ou mesmo quaisquer direitos às pessoas ou grupos "errados”" (p. 36). Carapanã também explica a ofensiva nazifascista contra o reconhecimento das diferenças culturais, o que para a

\footnotetext{
2 Para Almeida há uma distinção entre o conservadorismo clássico e o "neoconservadorismo". Enquanto o conservadorismo clássico, oriundo do século XVIII, buscava defender valores e instituições ameaçados pelas revoluções liberais, além de apresentar uma visão aristocrática de governo e um receio em face das proposituras democráticas, o neoconservadorismo se define como uma resposta ao Estado de bem-estar social, um combate à contracultura e à nova esquerda, marcados por uma profunda recusa das críticas sociais que efervesceram em várias partes do mundo na década de 1960.
}

PRACS: Revista Eletrônica de Humanidades do Curso de Ciências Sociais da UNIFAP https://periodicos.unifap.br/index.php/pracs ISSN 1984-4352 Macapá, v. 12, n. 2, p. 135-140, jul./dez. 2019 
nova direita seria uma tentativa comunista ${ }^{3}$ de enfraquecer a civilização e cultura ocidental e assim possibilitar a revolução. Este cenário descrito por Carapanã explicita a sinergia entre interesses econômicos e culturais da nova direita, que tende a defender pautas fascistas e nazistas que fortalecem o capitalismo e sua decorrente desigualdade social.

Já em As classes dominantes e a nova direita no Brasil contemporâneo, Flávio Henrique Calheiros Casimiro, professor de histórica econômica do Instituto Federal do Sul de Minas Gerais, faz um exercício semelhante ao de Carapanã, mas com o enfoque no caso brasileiro. Casimiro oferece uma série de informações sobre a constituição da nova direita do Brasil percorrendo sua constituição histórica a partir do surgimento de diversas organizações e institutos que objetivavam divulgar perspectivas teóricas de cunho neoliberal no país, em que seus aliados e principais favorecidos pertenciam às elites econômicas que tinham um enorme interesse na defesa e propaganda de tais pautas. Ainda que a nova direita no Brasil não seja homogênea, segundo Casimiro, ela obtém êxito em assegurar "[...] o essencial para a garantia dos seus interesses de acumulação de capital" (p. 46).

Ao nos depararmos com a ascensão da nova direita no Brasil, podemos nos perguntar se tal alavancada se deve ao financiamento de classe sociais dominantes interessadas na defesa de pautas neoliberais e (neo)conservadoras, ou se seria o poder militante de defensores/as desta perspectiva econômica, política e social de entender o mundo. Camila Rocha, cientista política, no texto denominado $O$ boom das novas direitas brasileiras: financiamento ou militância? procura responder essa questão. Para a autora, ao abordar a trajetória da nova direita desde os governos Lula até tempos atuais, não apenas a disponibilidade de recursos explica a ascensão da nova direita, mas também outros fatores, como "[...] a consolidação de laços e identidades comuns, mobilização de afetos e uso de redes sociais [...]” (p. 52), condições que superam em alguns casos o poder que os recursos financeiros ou de organização poderiam oportunizar.

Rosana Pinheiro-Machado - cientista social e antropóloga - e Lucia Mury Scalco - antropóloga - escrevem o texto Da esperança ao ódio: a juventude periférica bolsonarista. Fruto de uma etnografia longitudinal em desenvolvimento pelas autoras, o texto apresenta a percepção da transformação política que jovens residentes na periferia - além de suas famílias e seus entornos - sofreram pela emergência do crescimento e posteriormente colapso econômico que o Brasil experimentou nos últimos anos. Com a pesquisa, a autoras argumentam que a política de consumo não foi o bastante para possibilitar a inclusão desses jovens, demonstrando o seu fracasso especialmente na crise econômica que o Brasil começou a enfrentar em 2014. Pinheiro-Machado e Scalco explicam que toda essa conjuntura permitiu as brechas para que os jovens da periferia, agora abandonados pelo governo ao não poder mais consumir e, portanto, de sentirem-se "pertencidos", flertassem com outras formas de pertencer. No caso dos meninos, evidenciou-se o interesse deles pela figura de Jair Bolsonaro e de discursos reacionários. Já as meninas, em sentido oposto ao dos meninos, inclinaram-se a se declararem feministas, apresentavam argumentos mais consistentes e uma leitura mais crítica à figura de Jair Bolsonaro, o que revela a reivindicação das meninas por maior participação na po-

\footnotetext{
3 Carapanã discute no texto a noção de "marxismo cultural”, que é uma nova roupagem, com suas singularidades, de uma teoria conspiracionista de 1930: o bolchevismo cultural., bastante utilizada naquele tempo pelos nazistas e demais frentes de extrema-direita na Europa na defesa dos "valores tradicionais". A atualização do conceito surge na ala ideológica estadunidense, após o fim da Guerra Fria, com notórios interesses eleitorais. O "marxismo cultural" repercutiu nas eleições de 2018 no Brasil, usados por grupos de extrema direita. O perigo do acionamento desta teoria da conspiração, segundo Carapanã, se deve a sua íntima relação com ideais nazifascistas.
} 
lítica e no espaço público. Ainda sobre os meninos, a autoras expõem que dada as condições socioeconômicas que não mais permite o consumo como antes, a figura de um homem que irá mudar radicalmente suas condições de vida soa sedutor aos anseios desses jovens.

No texto seguinte, cujo título é Periferia e conservadorismo, Ferréz, escritor e militante, apresenta de maneira poética críticas e reflexões sobra a vida na periferia. Ferréz reverbera o conjunto de reflexões que perpassa toda a coletânea a partir de um olhar próximo da periferia, demonstrando como e o porquê de os discursos de ódio ressoarem neste universo multifacetado. A angústia transmitida pelo texto é aquela que o autor visualiza pelas pessoas que defendem ideias contraproducentes aos seus dilemas, mas que, com um olhar menos pedante e mais calcado na realidade popular, nos permite entender a forma pelas quais os moradores da periferia compreendem suas demandas políticas, sociais e econômicas.

Edson Teles, professor de filosofia da UNIFESP e militante da Comissão de Familiares Mortos e Desaparecidos Políticos da Ditadura, busca no texto A produção do inimigo e a insistência do Brasil violento e de exceção demonstrar como intensificou-se, desde junho de 2013, "[...] as ações de militarização da vida e da política, ações essas que foram fortalecidas com o golpe de 2016 contra a presidenta Dilma Rousseff' (p. 66). O autor explora a hipótese segundo a qual a leitura do mundo a partir de uma perspectiva binária e antagônica em que a violência, o militarismo e a ordem são valorizadas, à medida em que se produz "inimigos" que devem ser eliminados da sociedade para a concretização da paz, produz as condições ideias para o combate, pelo Estado, de grupos oprimidos, discriminados, e que resistem aos interesses dominantes. Neste cenário de criação de subjetividades para o controle e a disciplina, as subjetividades transformadoras tornam-se uma ameaça ao cidadão de bem e ao status quo, "permitindo" a eliminação dos/as indesejados/as com anuência da opinião pública.

Rubens Casara, doutor em direito e juiz de direito do Tribunal de Justiça (RJ), aborda o Poder Judiciário em Precisamos falar da "direita jurídica". Para Casara não se pode analisar o direito e as formas jurídicas sem concebê-los como aquelas que mantêm as estruturas de poder, cuja interpretação da norma depende da tradição daquele que o interpreta. No Brasil, Casara aponta que os atores jurídicos agem influenciados pela herança do período ditatorial, em que mesmo após a redemocratização do pais estes tendem “[...] a atuar no sistema de justiça com os mesmos valores e a mesma crença no uso abusivo da força que condicionavam a aplicação do direito no período de exceção” (p. 74). O Poder Judiciário, equivocadamente concebido como órgão que evitaria a barbárie garantindo o Estado democrático de direito, tornou-se, no Brasil e no mundo, um instrumento útil para os grupos dominantes. O autor finaliza o texto apresentando alguns sintomas na magistratura brasileira de sua potencialidade fascista, e assinala a importância da luta política como superação desta realidade.

Em $O$ discurso econômico da austeridade e os interesses velados, Pedro Rossi e Esther Dweck, docentes de economia da UNICAMP e UFRJ respectivamente, abordam como o discurso da austeridade busca de modo dissimulado convencer que a solução para qualquer problema social passa pela redução de gastos do Estado. Parte-se do princípio de que para que ocorra crescimento deve-se ajustar a economia, e isto implica em corte de gastos sociais. Para Rossi e Dweck, o discurso da austeridade não passa de um mito, isto porque "[...] as experiências históricas mostram que a austeridade é contraproducente, pois tende a provocar queda no crescimento e aumento da dívida pública, resultado contrário ao que se propõe” (p. 80), e não obstante, acaba por prejudicar os grupos sociais mais vulneráveis, visto que com a aplicação da austeridade os programas sociais são os mais afetados. Não bastaste a austeridade

PRACS: Revista Eletrônica de Humanidades do Curso de Ciências Sociais da UNIFAP https://periodicos.unifap.br/index.php/pracs ISSN 1984-4352 Macapá, v. 12, n. 2, p. 135-140, jul./dez. 2019 
não entregar aquilo que promete, os autores ainda evidenciam como esta prática se encaixa como um dos três pilares centrais do neoliberalismo, em conjunto com a liberação dos mercados e as privatizações. No caso do Brasil, conclui-se que a austeridade serve como ferramenta para combater direitos garantidos constitucionalmente, além de aprofundar as reformas neoliberais.

No texto seguinte, intitulado Antipetismo e conservadorismo no Facebook, o professor e doutor em ciência da computação Márcio Moretto Ribeiro apresenta um estudo sobre a polarização política nesta rede social, além de traçar os perfis dos usuários que se alinham com as comunidades antipetistas e anti-antipetistas. O estudo de Ribeiro nos ajuda a compreender os impactos das redes sociais na política brasileira, sobretudo em tempos em que o uso de aplicativos de mensagens e de notícias falsas - fake news - servem para influenciar eleitores/as a escolherem e defenderem propostas políticas, sociais e econômicas diametralmente opostas aos seus interesses.

Ainda que a religião apareça como tema em vários textos que compõem a obra, é Henrique Vieira, teólogo e cientista social, que a aborda de maneira central em seu texto. Em Fundamentalismo e extremismo não esgotam a experiência do sagrado nas religiões, Vieira discute a ascensão do fundamentalismo religioso no Brasil, que em articulação com grupos dominantes de outros campos, acaba por influenciar os rumos políticos do país. Com isso, grupos sociais, como os/as LGBTI, mulheres, e minorias religiosas tendem a terem seus direitos suprimidos pela ação de parlamentares que legislam violando a laicidade do Estado brasileiro. Mesmo o fundamentalismo religioso apresentando-se como entrave à garantia dos direitos humanos, Vieira advoga a ideia de que a religião também pode agir na perspectiva contrária, isto é, negando intepretações dogmáticas e intercedendo pelos direitos dos oprimidos. Neste sentido, concluí Vieira que precisamos combater as ações fundamentalistas religiosas que obscurantizam a política brasileira, ao mesmo tempo que devemos fortalecer as iniciativas de cunho religioso que se dedicam ao combate à intolerância e à opressão.

Lucas Bulgarelli - doutorando em antropologia pela USP - em Moralidades, direitas e direitos LGBTI nos anos 2010, apresenta uma análise sobre os eventos que dizem respeito aos direitos LGBTI no cenário nacional. Destaca a atuação de políticos conservadores, católicos e evangélicos, na constante oposição aos direitos de mulheres e LGBTI, este que garantem êxito ao não possibilitar que projetos de lei que propõe direitos a estes grupos sejam aprovados no Congresso. Ainda que essa movimentação de políticos religiosos contra essas minorias passe a impressão de que seja um fenômeno recente, Bulgarelli explica que tal empreitada fundamentalista e conservadora remonta desde a constituinte de 1988. Na conclusão, o autor faz uma reflexão sobre a pertinência do alcance social do conceito de gênero, para que sua compreensão abarque toda a sociedade e não apenas àqueles que compõem os movimentos sociais, afinal, "a defesa e a atualidade dos direitos LGBTI dependem, cada vez mais, de um esforço político centrado na politização, e não na desqualificação do debate” (p. 102).

Em Feminismo: um caminho longo à frente, Stephanie Ribeiro, arquiteta, urbanista, colunista e escritora corrobora com os apontamentos tanto de Bulgarelli como de Henrique Vieira, ao afirmar que "o apoio e avanço que políticos mais conservadores, ligados a certas vertentes religiosas como a evangélica, que misturam crenças com o seu fazer político, colocam em evidente temor todas as minorias sem acesso a direitos desse país” (p. 105). Segundo Ribeiro, ao ignorar a laicidade do país, políticos de todas as esferas do poder colocam em risco a vida de crianças. Por exemplo, ao negar que os debates sobre gênero e sexualidade ocorram nas 
escolas, é possível que crianças que sofram abuso não tenham as condições intelectuais para identificar este tipo de crime, tudo em nome de uma defesa vazia da "família tradicional brasileira”. Ribeiro apresenta a força que as feministas do Brasil demonstram ao lutar pelos direitos das mulheres e de outras minorias, além de apresentar uma análise crítica desta atuação. Ao relatar dois casos de violência contra mulheres que atuavam na política, quais sejam, o assassinato da vereadora Marielle Franco e o golpe contra a presidenta democraticamente eleita Dilma Rousseff, Ribeiro nos faz refletir sobre a luta histórica que feministas estão travando, que embora ameaçadas política e fisicamente, concebem uma das forças mais revolucionárias dos últimos tempos.

No último texto que compõe a obra Fernando de Araújo Penna, professor da Faculdade de Educação da UFF, discute em $O$ discurso reacionário de defesa de uma "escola sem partido" o avanço da direita no campo educacional. Ainda que muitas pessoas considerem que o projeto Escola sem Partido não necessite de maiores atenções tendo em vista sua inconstitucionalidade, Penna dispõe de bons argumentos para nos preocuparmos com o avanço reacionário nas escolas públicas e privadas no Brasil. Um deles é que, embora o projeto não tenha sido aprovado, seus efeitos já são visualizados, como a perseguição de docentes progressistas e a constante tentativa de proibir que se discuta nas escolas temas imprescindíveis para a formação cidadã dos/as jovens estudantes. Penna encerra afirmando que o período de retrocesso pode ser uma "[...] oportunidade para refundar nossa luta pela educação democrática e pela escola pública, enfrentando esses novos desafios e ameaças” (p. 113).

Os textos, em especial dos/as pesquisadores/as, ainda que não apresentem uma discussão pormenorizada sobre os métodos empregados nas análises, possibilitam um alcance para além do âmbito acadêmico, um triunfo da coletânea em face de uma visão deturpada que compõe o imaginário social e produz representações equivocadas e desonestas sobre a Universidade Pública. Ao sintetizarem os resultados de uma série de estudos que estão em desenvolvimento, destacam a importância das Universidades Públicas e seu potencial investigativo, hoje ameaçadas pelo desmonte da Ciência e da educação pública. Não obstante, o conhecimento produzido nesses espaços oportuniza uma defesa mais qualificada da democracia e dos direitos humanos, ideais que tendem ao colapso em tempos de ódio.

O livro cumpre um importante papel ao oferecer um compêndio de análises sobre a realidade brasileira e os efeitos da "reemergência" das direitas no Brasil. Em tempos de ódio como política, uma obra antifascista. 